\title{
Inflamação de queratoses seborreicas múltiplas induzida por quimioterapia com gencitabina *
}

\author{
Inflammation of multiple seborrheic keratoses induced by chemotherapy \\ with gemcitabine
}

\author{
Caio Roberto Shwafaty de Siqueira ${ }^{1}$
}

Hélio Amante Miot ${ }^{2}$

\begin{abstract}
Resumo: São diversos e comuns os efeitos mucocutâneos dos quimioterápicos, alguns por ação citotóxica, outros por hipersensibilidade ao fármaco. Os autores relatam a ocorrência de inflamação em múltiplas queratoses seborreicas pré-existentes, após terapia citorredutora com gencitabina, em paciente sob tratamento para neoplasia de pâncreas. Discutem, ainda, a benignidade do evento e alertam para a necessidade de adequada identificação dos efeitos cutâneos decorrentes da quimioterapia sistêmica.

Palavras-chave: Antineoplásicos; Antineoplásicos/efeitos adversos; Ceratose seborreica; Inibidores da síntese de ácido nucleico
\end{abstract}

\begin{abstract}
There are several common mucocutaneous adverse effects related to chemotherapy, either by direct cytotoxic action or by hypersensitivity to the drugs. The authors report inflammation in multiple seborrheic keratoses after chemotherapy with gemcitabine in a patient under treatment for pancreatic cancer. Moreover, they discuss the relative benignity of this event and warn about the need to correctly identify systemic chemotherapy-induced skin adverse effects.

Keywords: Antineoplastic agents; Antineoplastic agents/adverse effects; Keratosis, seborrheic; Nucleic acid synthesis inhibitors
\end{abstract}

\section{INTRODUÇÃO}

Queratoses seborreicas, ceratoses seborreicas ou verrugas seborreicas são lesões cutâneas benignas comuns na idade adulta, originadas da epiderme, usualmente acastanhadas, tendo como principal característica a proeminência folicular, com formação de pseudocistos e pseudoaberturas foliculares. O tórax é o local mais acometido, mas as lesões podem ocorrer em qualquer área do tegumento. ${ }^{1}$

Sua etiologia é desconhecida, com forte associação familiar, sendo mais comuns entre caucasianos. Recentemente, tem-se postulado que fatores de crescimento epidérmicos participam da sua gênese.

Eventos inflamatórios - como eczemas -, quimioterapia e neoplasias internas podem tanto levar ao surgimento de queratoses seborreicas como promover sua inflamação. ${ }^{2}$
O crescente uso de novas drogas quimioterápicas tem como consequência a ocorrência de novos efeitos adversos, cutâneos e não cutâneos. Os análogos de nucleosídeos (AN), dentre eles a gencitabina, são conhecidos pela possibilidade de causar inflamação súbita de queratoses seborreicas. ${ }^{3,4,5,6}$ Inflamação de queratoses actínicas e carcinomas espinocelulares também é relatada com outros quimioterápicos.

Os autores apresentam caso de inflamação de queratoses seborreicas após uso de gencitabina em paciente sob tratamento de neoplasia de pâncreas.

\section{RELATO DO CASO}

Mulher, branca, de 58 anos, apresentou quadro de icterícia súbita, sendo submetida a ultrassonografia de abdome, em que foi demonstrada dilatação do

Aprovado pelo Conselho Consultivo e aceito para publicação em 08.06.09.

* Trabalho desenvolvido em clínica privada.

Conflito de interesse: Nenhum / Conflict of interest: None

Suporte financeiro: Nenhum / Financial funding: None

Dermatologista especialista pela Sociedade Brasileira de Dermatologia (SBD).

Professor assistente doutor do Departamento de Dermatologia e Radioterapia da FMB - Universidade Estadual Paulista (Unesp) - Botucatu (SP), Brasil.

(C)2009 by Anais Brasileiros de Dermatologia
} 
canal de Wirsung, edema do pâncreas e coledocolitíase. Foi realizada derivação cirúrgica bílio-digestiva e retirada da vesícula biliar. O marcador tumoral CA 19.9, que estava aumentado, diminuiu consideravelmente nos meses seguintes à derivação cirúrgica.

Quatro meses após, a tomografia computadorizada de controle evidenciou massa expansiva na cabeça do pâncreas, associada a trombose e invasão de vasos circundantes, sendo a cirurgia desconsiderada pelo alto risco. Concomitantemente, o marcador CA 19.9 apresentou aumento expressivo.

Foi então indicado tratamento citorredutor, empregando quimioterapia com gencitabina. Após a segunda sessão, a paciente passou a apresentar prurido intenso nas múltiplas queratoses seborreicas préexistentes no tronco superior, que se tornaram edematosas, eritematosas e descamativas (Figuras 1 e 2).

O exame histopatológico demonstrou quadro de queratose seborreica com inflamação na derme subjacente, sem evidências de tecido neoplásico pancreático nas lesões (Figura 3).

Foi iniciado o uso de anti-histamínico oral e corticoide tópico de média potência, com controle completo do quadro, sem necessidade de interrupção das sessões de quimioterapia.

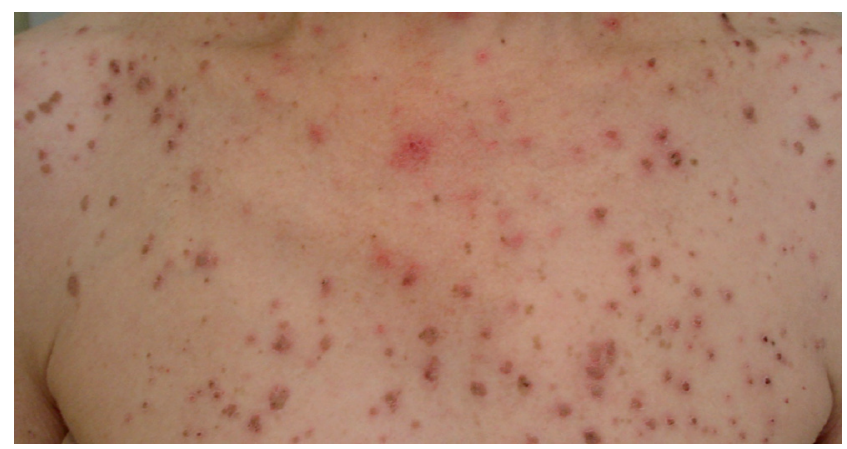

FiguRA 1. Queratoses seborreicas inflamadas no tronco superior

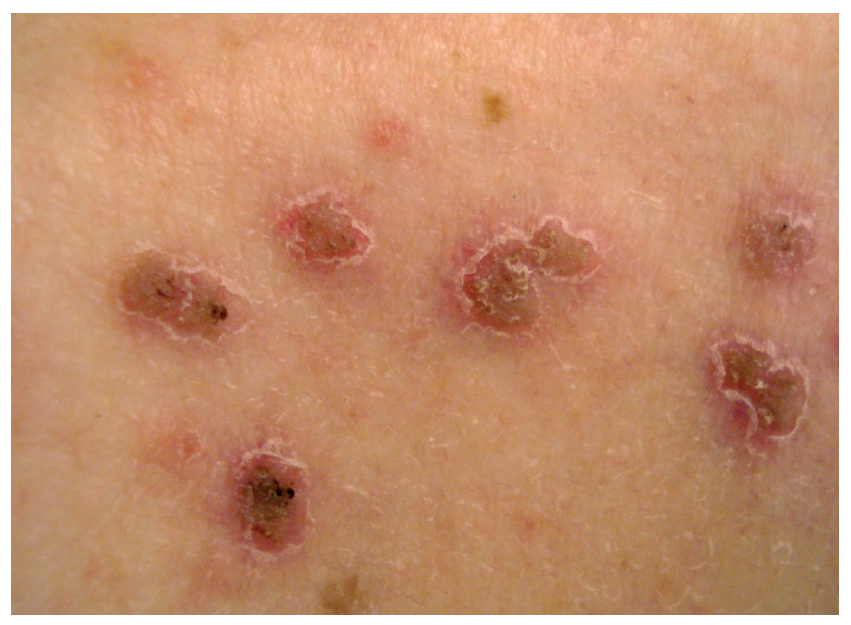

Figura 2. Detalhe das queratoses seborreicas, evidenciando eritema, edema e descamação

\section{DISCUSSÃO}

Os agentes quimioterápicos são amplamente utilizados para tratamento de neoplasias e doenças autoimunes, tendo papel principal ou adjuvante. ${ }^{2}$ Os efeitos adversos causados pela terapia são inúmeros e comuns, alguns deles dose-dependentes (Quadro 1).

Tais efeitos podem ocorrer por ação tóxica direta-que é o mecanismo mais frequente, causando, por exemplo, estomatite e alopecia -, por indução de inflamação ou por hipersensibilidade. .,2,8 $^{-1}$

Tecidos com alto índice de renovação celular, como a pele e seus anexos, são frequentemente afetados, levando a transtornos na qualidade de vida do paciente. $^{7}$

Alguns efeitos são previsíveis, como estomatite erosiva, aftose ou alopecia por eflúvio anágeno. Outros são menos observados, como hiperpigmentação cutânea e inflamação de tumores cutâneos benignos.

Há alguns padrões de efeitos adversos promovidos por quimioterápicos específicos, como a dermatite flagelada que ocorre no tratamento com a bleomicina ${ }^{9}$ e as erupções acneiformes induzidas pelo tratamento com inibidores do fator de crescimento epidérmico, representando, inclusive, indício de boa evolução terapêutica. ${ }^{10}$

Existem raros casos, descritos na literatura, de inflamação de queratoses seborreicas induzida por AN (citarabina) usados no tratamento de pacientes com neoplasias malignas, principalmente das linhagens hematológica e pulmonar. ${ }^{3,5,6,8}$

A gencitabina, usada no caso descrito, é um recente AN em uso no tratamento antineoplásico. Age após fosforilação no meio intracelular, inibindo a enzima ribonucleotídeo-redutase e incorporando-se à fita de DNA que está sendo duplicada. Causa, então, bloqueio da divisão celular entre as fases G1 e S do ciclo celular, culminando na morte da célula. ${ }^{11}$

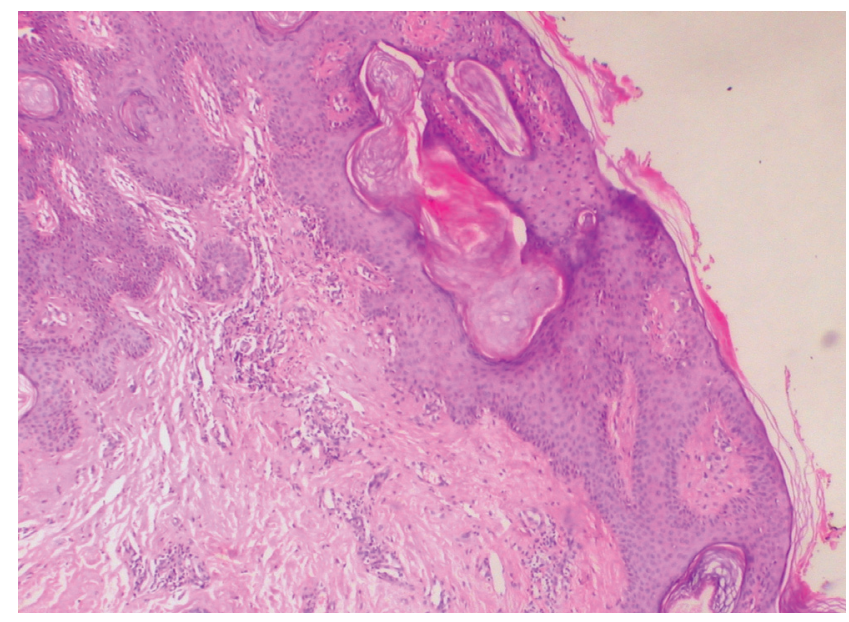

Figura 3. Detalhe do exame histopatológico (HE, 400 x) 
QuAdro 1. Principais efeitos adversos mucocutâneos relacionados a quimioterápicos, causados por citotoxicidade $(\mathrm{T})$ ou por hipersensibilidade ao fármaco $(\mathrm{H})$

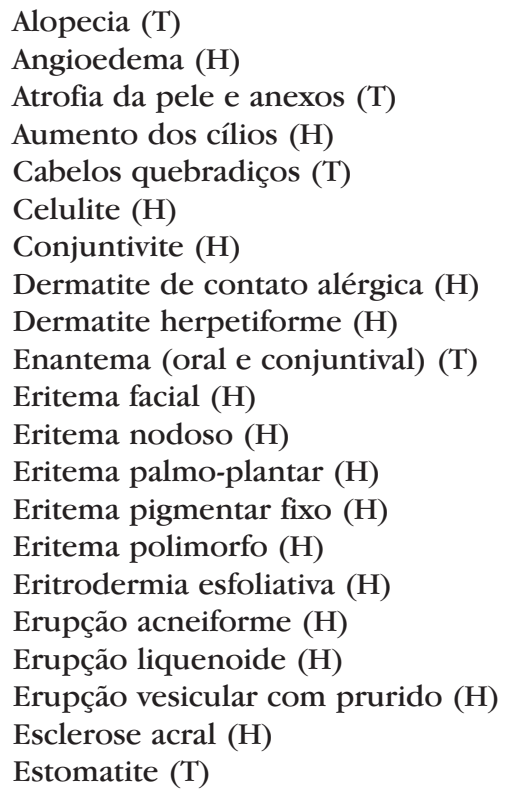

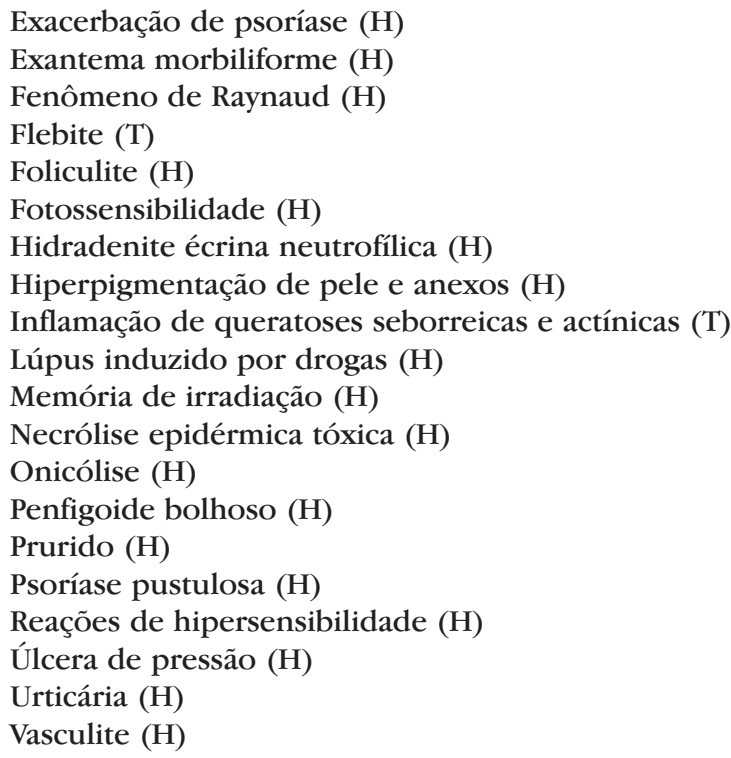

Não se conhece completamente o mecanismo desse processo. Admite-se que a inflamação das queratoses seborreicas ocorra como efeito citotóxico direto aos queratinócitos. A possibilidade de que o tumor secrete peptídeos de crescimento e que o quimioterápico interrompa esse ciclo, levando à inflamação, foi uma das explicações aventadas, justificando, inclusive, a gênese do fenômeno de Leser-Trélat. ${ }^{10}$ Porém, a existência de fenômenos de hipersensibilidade não pode ser descartada, visto que o infiltrado linfocitário dérmico está associado à inflamação dessas lesões cutâneas.

Quando um AN causa inflamação apenas nas queratoses seborreicas pequenas, pode clinicamente simular herpes zoster disseminado. ${ }^{3}$ Lesões maiores, que mesmo inflamadas mantêm as características de queratose seborreica, ajudam na diferenciação de outros quadros vesiculosos. O exame histopatológico também pode contribuir para o diagnóstico desses casos.
Além das drogas citadas, 5-fluoruracil, docetaxel, vincristina, doxorrubicina, dactinomicina e cisplatina também podem promover inflamação em queratoses seborreicas. ${ }^{4}$

Erupções medicamentosas, exantemas virais, infecções fúngica e bacteriana e metástases cutâneas de neoplasia primária são diagnósticos diferenciais a ser considerados. ${ }^{7,8}$

Configurando uma reação autolimitada, não se contraindica o uso de AN na vigência de inflamação de queratoses seborreicas por eles induzida. Pode ou não haver recorrência da inflamação quando da re-exposição aos AN. ${ }^{5,7}$

O dermatologista deve estar atento e saber reconhecer precocemente os efeitos adversos provocados por quimioterápicos. Deve também instituir o devido tratamento, para que não se interrompa o planejamento oncológico proposto.

\section{AGRADECIMENTO}

Ao patologista Dr. Mauro Roberto M. B. Monteiro pelo exame histopatológico e pela fotomicrografia. 


\section{REFERÊNCIAS}

1. Ho, CYV. Tumores epiteliais benignos. In: Freedberg MI, Eisen AZ, Wolff K, Austen KF, Goldsmith LA, Katz SI, Fitzpatrick TB, editores. Fitzpatrick tratado de dermatologia. 5 ed. Rio de Janeiro: Revinter; 2005. p.873-6.

2. Fitzpatrick JE, Yokel BE, Hood AF. Complicações mucocutâneas da terapia anti-neoplásica. In: Freedberg MI, Eisen AZ, Wolff K, Austen KF, Goldsmith LA, Katz SI, Fitzpatrick TB (editores). Fitzpatrick tratado de dermatologia. 5 ed. Rio de Janeiro: Revinter; 2005. p.1642-53.

3. Patton T, Zirwas M, Nieland-Fisher N, Jukic D. Inflammation of seborrheic keratosis caused by cytarabine: a pseudo sign of Leser-Trelat. J Drugs Dermatol. 2004;3:565-6.

4. Williams JV, Helm KF, Long D. Chemotherapy-induced inflammation in seborrheic keratoses mimicking disseminated herpes zoster. J Am Acad Dermatol. 1999;40:643-4.

5. Chu CY, Yang CH, Chiu HC. Inflammation of seborrheic keratoses due to docetaxel treatment. Acta Derm Venereol. 2001;81:316-7.

6. Kechijian P, Sadick NS, Mariglio J, Schulman P. Cytarabine-induced inflammation in the seborrheic keratoses of Leser-Trelat. Ann Intern Med. 1979;91:868-9.

7. Susser WS, Whitaker-Worth DL, Grant-Kels JM. Mucocutaneous reactions to chemotherapy. J Am Acad Dermatol. 1999;40:367-98.

8. Chun YS, Chang SN, Oh D, Park WH.. A case of cutaneous reaction to chemotherapeutic agents showing epidermal dysmaturation. J Am Acad Dermatol. 2000;43:358-60.

9. Silveira JCG, da Cunha BM, Estrella RR. Dermatite flagelada induzida pela bleomicina. An Bras Dermatol. 2006;81:83-5.

10. Lee MW, Seo CW, Kim SW, Yang HJ, Lee HW, Choi JH, et al. Cutaneous side effects in non-small cell lung cancer patients treated with Iressa (ZD1839),

an inhibitor of epidermal growth factor. Acta Derm Venereol. 2004;84:23-6.

11. Gemzar (Gemcitabine $\mathrm{Hcl}$ ) Drug Information: uses, side effects, drug interactions and warnings [homepage on the Internet]. RxList. [acesso 20 Out 2008]. Disponível em: http://www.rxlist.com/ gemzar-drug.htm.

\footnotetext{
ENDEREÇO PARA CORRESPONDÊNCIA / MAILING ADDRESS: Caio Roberto Shwafaty de Siqueira

Rua Diana, 409/104

05019-000 São Paulo SP

Tel.Ifax: $1136624869112579-3868$

e-mail: caioshwafaty@yahoo.com
}

Como citar este artigo/How to cite this article: Siqueira CRS, Miot HA. Inflamação de queratoses seborreicas múltiplas induzida por quimioterapia com gencitabina. An Bras Dermatol. 2009;84(4):410-3. 